\title{
COMPARACIÓN DE LOS PROBLEMAS FITOSANITARIOS EN ORQUÍDEAS DE POBLACIONES SILVESTRES Y DE CULTIVO, COMO EVALUACIÓN DE RIESGOS DE PLAGAS O EPIDEMIAS
}

\author{
Willy Salazar-Casasa ${ }^{1,4}$, German Rivera-Coto ${ }^{2} \&$ Gilberto Corrales-Moreira $^{3}$ \\ ${ }^{1}$ Universidad Nacional, Heredia, Costa Rica \\ ${ }^{2}$ Laboratorio de Fitopatología, Universidad Nacional, Apartado 86-3000, Heredia, Costa Rica \\ ${ }^{3}$ Laboratorio de Entomología, Universidad Nacional, Apartado 86-3000, Heredia, Costa Rica \\ ${ }^{4}$ Autor para correspondencia: willacko@hotmail.com
}

PALABRAS ClAVE: orquídeas, plagas, entomología , enfermedades, patógenos, fitopatología

\begin{abstract}
Introducción
Los ecosistemas naturales mantienen un autocontrol de poblaciones, que es afectada por factores exógenos. Mientras que en sistemas alterados se necesitan controladores exógenos para mantener un cierto tipo de equilibrio (p.e. prácticas culturales, uso de agroquímicos, subsidios de materia y energía, etc).

Las orquídeas que viven en condiciones alteradas suelen presentar problemas fitosanitarios, donde es necesario la intervención humana para asegurar la conservación de dichas especies, no así en medios naturales, pues existen mecanismos que controlan dichos problemas (Rivera 1999).

Aunque hay información del cultivo de las orquídeas que se venden comercialmente, son pocos los datos en este campo de especies silvestres. La dificultad en la medición de las demandas minerales y la desigualdad de requerimientos dificulta un estudio de necesidades nutricionales (Benzing 1990). Para el desarrollo pleno de las orquídeas es necesario de los factores propicios como son: luz, humedad, aireación, nutrición y control fitosanitario (Rivera 1998).

Las razones de documentar los diferentes problemas fitosanitarios en orquídeas son:
\end{abstract}

1. La poca información de interrelaciones biológicas entre orquídeas y sus antagonistas.

2. La destrucción de zonas silvestres, que propicia condiciones de desbalance y se afecta negativamente la conservación de muchas especies, entre ellas las orquídeas.

3. El traslado de orquídeas del estado natural a otro ambiente puede aumentar el riesgo de problemas fitosanitarios; facilitándose la diseminación de los mismos en viveros, colecciones privadas o jardines botánicos.

4. Estudios recientes revelan patógenos y artrópodos que afectan las orquídeas: AOS (1975), Rivera (1998), Cárdenas (2003), Amorosi (2004), Gutiérrez (2005), Corrales y Rivera (2003) y Rivera y Corrales (2003a, 2003b, 2005). Los problemas fitosanitarios documentados son variados pero no se conoce completamente las diferencias entre los ambientes naturales y los de cultivo.

En esta investigación se elabora una lista de agentes que afectan el desarrollo de las orquídeas en dos condiciones: natural (Zona Protectora Cerros de la Carpintera, Cartago) y artificial (Orquideario 25 de Mayo, Sabanilla de Montes de Oca). Se presentan dos poblaciones de orquídeas silvestres en condiciones climáticas similares pero en distintos ambientes.

\section{Antecedentes}

Zona Protectora Cerros de la Carpintera. La Zona Protectora Cerros de La Carpintera (ZPCC) fue creada mediante Decreto Ejecutivo 6112-A del 23 de junio de 1976. Mide cerca de 2.396 has y su manejo se rige por la Ley General Forestal No. 7575 del 13 de febrero de 1996. La ZPCC se localiza al sureste de San José. La cima de los cerros es divisoria de aguas entre la vertiente Atlántica y la vertiente Pacífica. Los tres picos más altos tienen alturas entre los $1.800 \mathrm{y}$ $1.855 \mathrm{~m}$. Otras alturas son el Cerro Quirazú (1.794 $\mathrm{m})$, Alto Lima (1.651 m) y Alto Negro $(1.747 \mathrm{~m})$. El área de la ZPCC se distribuye entre los cantones de La Unión (974 has), Cartago (964 has), Desamparados (429 has) y Curridabat (28 has); donde 
Cuadro 1.Uso de Tierra. Según el Sistema Nacional de Áreas de Conservación (SINAC), el uso de la tierra en la Zona Protectora.

\begin{tabular}{l|c|c} 
Uso de tierra & Área & Porcentaje \\
\hline Bosque primario & 618 has & $26 \%$ \\
\hline Bosque secundario & 194 has & $8 \%$ \\
\hline Charral & 57 has & $2 \%$ \\
\hline Cultivos y pasto & 769 has & $32 \%$ \\
\hline Suelo desnudo y ciudades & 256 has & $11 \%$ \\
\hline Reforestación/recuperación & 502 has & $21 \%$ \\
\hline Total & 2396 has & $100 \%$ \\
\hline
\end{tabular}

el cantón de la Unión tiene la mayor riqueza natural. La precipitación anual es de 1.500 a $2.500 \mathrm{~mm}$ y la temperatura anual de 15 a $23^{\circ} \mathrm{C}$ (Ossenbach et al 2003) (Cuadro 1).

Orquideario 25 de Mayo. El Orquideario 25 de Mayo es una colección privada de orquídeas inscrita ante el MINAE como vivero artesanal desde el 8 de Julio del 2003 por medio de la resolución OSJ-SC-No $\mathrm{V}-001$. Cuenta con más de 800 plantas en condiciones de cultivo con un plan manejo e identificación de especies. Está constituida por colectas a nivel nacional con el fin de facilitar los esfuerzos de conservación in vivo, y para investigación con la colaboración del Jardín Botánico Lankester. Está ubicado en el distrito de Sabanilla del cantón de Montes de Oca en la provincia de San José; a una altitud de 1.250 m.s.n.m con una precipitación anual de $1.900 \mathrm{~mm}$ y una temperatura anual de $20^{\circ} \mathrm{C}$.

\section{Marco teórico}

Los problemas fitosanitarios son procesos naturales que afectan todos los cultivos. Son tan frecuentes y comunes tanto en la naturaleza como en cultivo (Rivera 1998).

En un ecosistema hay mecanismos reguladores de las poblaciones de organismos. En estado natural, las orquídeas forman parte de un sistema como ese, interactúan equilibradamente con otros seres vivos, así sus poblaciones sobreviven y se multiplican libremente. Cuando estas plantas se extraen de su ambiente natural y se colocan en plantaciones y colecciones, el balance natural se rompe y se incrementan algunos organismos antagonistas, cuya densidad puede afectar o deteriorar el cultivo
(Cárdenas 2003). Además que se pueden presentar nuevas interrelaciones con otros organismos ajenos al hábitat original o la pérdida de otras interrelaciones afectando el funcionamiento de las plantas (Rivera 1998).

Entre las amenazas para la supervivencia de las orquídeas están las enfermedades infecciosas que pueden estar en forma silenciosa. La principal diseminación es el trasiego de materiales enfermos con infecciones latentes o con síntomas conspicuos (Rivera y Corrales 2005)."El predatorismo hacia las orquídeas es frecuente en los ecosistemas naturales y puede convertirse en plaga cuando se trata de plantas cultivadas" (Rivera 1998).

Las orquídeas en su hábitat natural tienen un excelente balance para desarrollarse a plenitud. Pero el mantenimiento de las mismas en colección o vivero requiere de un plan de manejo, así como una atención constante. Para que las plantas no se deterioren se necesita del tiempo, el conocimiento o los recursos apropiados.

\section{Metodología}

Procedimientos. Se recolectaron orquídeas que presentaron problemas fitosanitarios de las dos zonas de estudio. Las muestras recolectadas fueron empacadas, etiquetadas y llevadas al laboratorio para el análisis respectivo.

ENFERMEDADES. Se recolectaron plantas completas o secciones de las mismas, según el grado de la enfermedad. En el Laboratorio de Fitopatología de la Escuela de Ciencias Agrarias (ECA) de la UNA se realizó el proceso de diagnóstico e identificación, usando los procedimientos tradicionales según las técnicas correspondientes al tipo de patógeno. En el caso de plantas con virus no se aplicaron las técnicas moleculares, solo se describieron los síntomas correspondientes.

INSECTOS. Se recolectaron e identificaron aquellos individuos asociados al daño evidente en la orquídea. En el caso de insectos inmaduros se recolectó la planta completa para desarrollar las formas adultas en el laboratorio de Entomología de la ECA. Si no se presentó el agente causal de los daños se especuló sobre el posible causante.

\section{Resultados}

\section{ENFERMEDADES}

Antracnosis. Esta es la enfermedad más común en las orquídeas cultivadas en los trópicos. Se encontró ata- 
cando hojas, flores, seudobulbos y brotes jóvenes. En las hojas produjo manchas ovaladas, circulares o de forma irregular, color café oscuro, negras o grisáceas. En hojas carnosas se observaron hundidas y con un borde bien definido. Las hojas delgadas muestran lesiones de color y forma similar con un hundimiento leve o ausente. En estados avanzados se observaron acérvulos organizados en anillos concéntricos o líneas curvas. En los seudobulbos las lesiones fueron ovaladas o irregulares, con un hundimiento muy marcado y colores que van de café rojizo a negro (según la especie). El agente causal de la enfermedad fue Glomerella sp. (teliomorfo) o Colletotrichum sp. (amorfo, forma más frecuente).

Marchitez. Es una enfermedad vascular, que presentó pudriciones secas en las raíces y rizomas de las orquídeas, asociadas a coloraciones púrpura o rosa en el rizoma. Se identificó por un decaimiento de la planta, coloración verde claro o amarillenta de los seudobulbos y acucharamiento de las hojas (principalmente aquellas de tipo carnosas). Es causada por Fusarium spp.

Pudrición negra. Se presentó en todas las partes de la planta. En follaje causó manchas negras o café oscuro de consistencia suave, las lesiones avanzadas cubrieron la hoja e inclusive las partes basales (tallos, seudobulbos, rizomas y raíces). "Es causada por Phytophthora spp. y Pythium spp" (Rivera 1998). Esta enfermedad se favorece por condiciones de mucha humedad, poca aireación y poca luminosidad.

Cercosporiosis. Inicia con pequeños puntos amarillos en la superficie de la hoja, luego se hacen visibles en la parte superior. Presentó patrones como parchones con clorosis o puntos marrones esparcidos a lo largo de la hoja. En estado avanzado las manchas coalescen deteriorando gran parte de las hojas. El patógeno fue Cercospora spp.

Roya. Esta enfermedad es poco frecuente en orquidearios. Se identificó por pústulas generalmente en el envés de la hoja. Solamente se encontró ocasionado por Uredo sp.

Patógenos de suelo. Los patógenos identificados fueron: Pythium sp. y Rhizoctonia spp. y Verticilium sp. Se presentaron causando necrosis del tallo a nivel cortical.
Enfermedades causadas por bacterias. En las hojas se produjeron manchas negras con un halo de apariencia acuosa o aceitosa; mientras que en seudobulbos fueron pudriciones suaves generalmente con líquidos de olor desagradable. La bacteria asociada fue del género Erwinia.

Enfermedades causadas por algas. Es una enfermedad de tipo cosmética. Inicia con manchas negras en el haz de las hojas, luego se forman motas amarillas. Se produjo por Cephaleurus virescens Kunze.

Enfermedades causadas por Virus. "Los síntomas son poco seguros para dar un buen diagnóstico, varían mucho aún en un mismo hospedero" (Rivera 1998). Hay gran cantidad de investigación de virus en orquídeas (Pupulin, comentarios personales 2005), esto permite que "se puedan asociar ciertos síntomas a la conclusión de que sean provocados por virus sin necesidad de efectuar pruebas biomoleculares" (Rivera, Comentarios personales 2005). Los síntomas fueron: clorosis, mosaicos, anillos necróticos. En otros casos presentaron forma ojival formada por manchas necróticas o cloróticas.Las orquídeas que presentaron síntomas asociados a presencia de virus se encontraron solamente en el Orquideario 25 de Mayo.

Quemaduras de sol. Es una enfermedad abiótica por sobreexposición de la planta a la luz solar que deteriora los tejidos, causando: amarillamiento generalizado, crecimiento pobre o quemaduras. Los síntomas fueron quemaduras o edemas en hojas y seudobulbos. Inicia mostrando áreas verde claro con bordes indefinidos; luego cambian a color blanco-plateado y finalmente se tornan café o negro. "Este daño es cosmético, pero permite la entrada de patógenos" (Rivera 1998) El resumen de las enfermedades se presenta en el Cuadro 2.

\section{INSECTOS}

Defoliación sin presencia del agente causal. Se presentaron hojas y seudobulbos de orquídeas con diferentes tipos de daños mecánicos posiblemente ocasionados por insectos herbívoros generalistas: grillos (fam: Gryllidae), chapulines (fam: Acrinidae), larvas de mariposas (Lepidópteros), picudos (fam: Curculionidae) o crisomélidos (fam: Chrysomelidae).

Defoliación con presencia del agente causal. Fueron defoliaciones en hojas y flores causados por larvas de mariposas, crisomélidos y picudos. 
CUADRO 2. Enfermedades identificadas.

\begin{tabular}{|c|c|c|}
\hline $\begin{array}{c}\text { Nombre de } \\
\text { la enfermedad }\end{array}$ & $\begin{array}{l}\text { Género de orquídeas del } \\
\text { Orquideario } 25 \text { de Mayo }\end{array}$ & $\begin{array}{l}\text { Género de orquídeas } \\
\text { del ZPCC }\end{array}$ \\
\hline Antracnosis & $\begin{array}{l}\text { Acineta, Cochleantes, Elleanthus, Epidendrum, } \\
\text { Guarianthe, Huntleya, Kefersteinia, Laelia, } \\
\text { Lockhartia, Maxillaria, Octomeria, Oncidium, } \\
\text { Pescatorea, Pleurothallis, Prosthechea, } \\
\text { Rossioglossum, Sobralia, Stelis, Stenorrhynchus, } \\
\text { Tricopilia, Trigonidium, Vanilla }\end{array}$ & $\begin{array}{l}\text { Elleanthus, Epidendrum, Maxillaria, } \\
\text { Oerstedella, Oncidium, Pleurothallis, } \\
\text { Prosthechea, Schaphyglotis, Sobralia, Stelis, } \\
\text { Warczewiczella, Xylobium }\end{array}$ \\
\hline Marchitamiento & $\begin{array}{l}\text { Brassia, Encyclia, Guarianthe, Kefersteinia, } \\
\text { Laelia, Maxillaria, Oncidium, Osmoglossum }\end{array}$ & Maxillaria, Prosthechea \\
\hline Pudrición negra & Guarianthe, Rossioglossum & Prosthechea \\
\hline Cercosporiosis & Maxillaria, Stelis, Trigonidium & Epidendrum radicans \\
\hline Roya & No se presentó & Pleurothallis, Maxillaria \\
\hline Patógenos de suelo & No se presentó & Prosthechea, Epidendrum, Stelis, Lepanthes \\
\hline Bacteriosis & $\begin{array}{l}\text { Brassia, Coelipsis, Eriposis, Hexisea, } \\
\text { Maxillaria, Pleurothallis, Prosthechea livida, } \\
\text { Xylobium }\end{array}$ & Maxillaria, Prosthechea, Stelis \\
\hline C. virescens & Sobralia, Stelis & No se presentó \\
\hline Síntomas asociados a virus & Cymbidium, Oncidium, Stanhopea, Tricopilia & No se presentó \\
\hline Quemaduras de sol & $\begin{array}{l}\text { Elleanthus, Guarianthe, Laelia, Maxillaria, } \\
\text { Oncidium, Pleurothallis, Stelis, Vanilla }\end{array}$ & Maxillaria, Pleurothallis, Sobralia \\
\hline
\end{tabular}

Polilla harinosa. Los daños por este insecto se manifestaron por un decaimiento de la planta y poco crecimiento. Las larvas de este insecto comen las raíces y con cierta frecuencia los seudobulbos. Los signos fueron los excrementos negros y grises presentes en el sustrato. Son larvas de color gris o café rojizo que forman un capullo con una seda blanca muy resistente y envueltas con las mismas excretas del insecto.

Minas y Galerías. Se presentaron de varias formas y tamaños, principalmente en hojas carnosas: variedad de serpentinas y minas regulares. Los insectos que se encontraron causando daños fueron especies de Diptera, Lepidoptera y Coleoptera (Curculionidae). Las galerías fueron de dos formas: agujeros dispuestos a lo largo de las hojas (sin un patrón definido) y agujeros a lo largo de la vena central de las hojas. Las minas y galerías inactivas pudieron ser ocasionadas por los antes mencionados o por Hymenopteros.

Agallas en raíces. Se presentaron en las puntas de las raíces, por oviposiciones de picudos y un euritomido (Orden Hymenoptera), causando anomalías en el crecimiento celular.

Hojas con pinchaduras. Fueron lesiones hechas por chinches u otros insectos que se alimentan de savia.

Escamas. Las escamas se presentaron en hojas, seudobulbos e inflorescencias. Al nutrirse de la savia de las plantas causaron coloración amarillenta o depresiones del tejido.

Áfidos Se presentaron en inflorescencias, nuevos brotes y algunas hojas adultas, succionando savia de los tejidos. El resumen de las enfermedades se presenta en el Cuadro 3.

\section{Conclusiones}

En los dos ambientes estudiados se presentaron con mayor frecuencia antracnosis y defoliación por insectos masticadores. Sin embargo fueron más frecuentes los problemas fitosanitarios en el Orquideario 25 de Mayo que en la ZPCC; posiblemente por condición de desequilibrio ambiental o por mayor hacinamiento en estado de cultivo.

En la ZPCC se observó una mayor concentra- 
CUADRo 3 Daños provocados por insectos.

\begin{tabular}{|c|c|c|}
\hline Daño & $\begin{array}{l}\text { Género de orquídeas del } \\
\text { Orquideario } 25 \text { de Mayo }\end{array}$ & $\begin{array}{c}\text { Género de orquídeas del } \\
\text { ZPCC }\end{array}$ \\
\hline $\begin{array}{l}\text { Defoliaciones sin presencia del agente } \\
\text { causal }\end{array}$ & $\begin{array}{l}\text { Epidendrum, Oerstedella, Oncidium, } \\
\text { Pleurothalis }\end{array}$ & $\begin{array}{l}\text { Elleanthus, Encyclia, Epidendrum., } \\
\text { Maxillaria, Oerstedella, } \\
\text { Ornithocephalus, Pleurothallis, } \\
\text { Prosthechea, Schaphyglotis, } \\
\text { Warczewiczella, Xylobium }\end{array}$ \\
\hline Curculionidos & Oerstedella, Pleurothallis & $\begin{array}{l}\text { Epidendrum*, Oerstedella*, } \\
\text { Pleurothallis*, Stelis* }\end{array}$ \\
\hline Chrysomelidos & Epidendrum & Epidendrum*, Pleurothallis* \\
\hline Polilla harinosa & $\begin{array}{l}\text { Brassia } * \text {, Maxillaria, Oncidium, } \\
\text { Pleurothallis }\end{array}$ & No se presentó \\
\hline Minas & Maxillaria & Epidendrum, Pleurothallis, Stelis \\
\hline Galerías* & $\begin{array}{l}\text { Arpophyllum, Encyclia, Prosthechea, } \\
\text { Vanilla }\end{array}$ & $\begin{array}{l}\text { Encyclia, Epidendrum, Pleurothallis, } \\
\text { Schaphyglottis, Stelis }\end{array}$ \\
\hline Afidos & Encyclia, Oncidium, Oerstedella & Oerstedella \\
\hline Escamas & $\begin{array}{l}\text { Elleanthus, Guarianthe, Laelia, } \\
\text { Oncidium, Pescatorea, Schaphyglottis }\end{array}$ & Maxillaria \\
\hline Hojas con pinchaduras* & Laelia, Pleurothallis, Prosthecea & Oerstedella \\
\hline Agallas en raíces & Arpophyllum & Epidendrum, Oerstedella \\
\hline
\end{tabular}

ción de problemas fitosanitarios en zonas con alteraciones o procesos de equilibrio ecológico; pero en zonas de Bosque Primario no hubo problemas sanitarios importantes.

La presencia de enfermedades latentes o insectos potencialmente plagas, son uno de los problemas que considero de suma importancia, en el marco de la manipulación de orquídeas tanto de condiciones de cultivo como de zonas naturales.

Para efectos de la conservación de orquídeas se debe seguir la investigación de problemas fitosanitarios; ya que hay diversidad de agentes que pondrían en riesgo el desarrollo pleno de estas plantas. Entre tanto se favorezca el deterioro de los ecosistemas o se de un mal manejo a colecciones in vivo, se estaría amenazando la biodiversidad en general. Los problemas fitosanitarios en orquídeas llegan a sumarse a la lista de peligros que directa o indirectamente ponen en riesgo la diversidad de esta familia, como son: la deforestación, trasiego ilegal de plantas, contaminación ambiental y erosión genética.

Como consideración final es apropiado llamar la atención a todo aquel interesado en el mundo de las orquídeas, donde hay que tener muy claro el manejo apropiado, así como el conocimiento para mantener y cuidar esta familia.

Este estudio podría servir de herramienta para futuras investigaciones sobre otras interrelaciones antagónicas.

Agradecimientos. Se agradece a las siguientes entidades: Escuela de Ciencias Agrarias (UNA), Escuela de Biología (UCR), Jardín Botánico Lankester y Orquideario, 25 de Mayo, MINAE y Herbario Nacional. Además se agradece propietarios de fincas de la Zona Protectora Cerros de la Carpintera.

\section{LITERATURA CITADA}

American Orchid Society. 1975. Handbook on Orchid Pests and Diseases. AOS. Inc. Cambridge, Massachusets, U.S.A. 113 p.

Amorosi Mellado, R. 2004. Orquídeas Así hice mi vivero. Reglas prácticas de cultivo, desarrollo y mantenimiento de orquídeas. San José Costa Rica. Sociedad Editora Alquimia 2000. 63 p.

Benzing, D. 1990. Vascular epiphytes. New York, USA. Cambridge University Press 354 p.

Cárdenas Briceño, C. 2003. Diagnóstico de las enfermedades que afectan las orquídeas cultivadas en el Valle Central de Costa Rica. Heredia, Costa Rica. Escuela de Ciencia Agrarias, UNA. 165 p 
Corrales, G. \& G. Rivera. 2003. Principales artrópodos asociados con colecciones y viveros de orquídeas en la región del pacífico sur de Costa Rica. Memoria de Congreso Alianza Tecnológica para la Agricultura con Calidad. San José CR. pag. 54.

Gutiérrez, C. 2005. Diferencias de patotipos del hongo Colletotrichum gloesporioides, que ataca en los invernaderos comerciales y en un Jardín Botánico en el Valle Central de Costa Rica. Escuela de Ciencias Agrarias. Heredia. C.R. $49 \mathrm{p}$

Ossenbach C., M. Ossenbach \& F. Pupulin. 2003. Catalogo Preliminar Anotado de las Orchidaceae de la Zona Protectora Cerros de la Carpintera. Orquideario 25 de mayo, San José Costa Rica. 41 p

Rivera Coto, G. 1998. Orquídeas Generalidades y Cultivo. Heredia, Costa Rica. Editorial Fundación UNA. 266 p.

Rivera Coto, G. 1999. Conceptos Introducción a la fitopa- tología. San José, Costa Rica. Editorial Universidad Estatal a Distancia. 308 p.

Rivera, G. \& G. Corrales. 2003a. Principales enfermedades fungosas diagnosticadas en colecciones y viveros de orquídeas en la región del pacífico sur de Costa Rica. Memoria de Congreso Alianza Tecnológica para la Agricultura con Calidad. San José CR. pag. 27.

Rivera, G. \& G. Corrales. 2003b. Principales enfermedades de orquídeas causadas por oomycetes, bacterias y algas en colecciones y viveros en la región del pacífico sur de Costa Rica. Memoria de Congreso Alianza Tecnológica para la Agricultura con Calidad. San José CR. pag. 28

Rivera, G. \& G. Corrales. 2005. Estudio de las enfermedades que afectan las orquídeas en Costa Rica. Revista Ticorquídeas.1(1):13-14.

Willy Salazar Casasa es Ingeniero Agrónomo de la Universidad Nacional. Con conocimiento en la horticultura diagnóstico de problemas fitosanitarios de orquídeas. Ha participado en Congresos de Orquideología y Fitopatología en Costa Rica como colaborador. Ha colaborado ad honorem en el Jardín Botánico Lankester y en el proyecto de investigación: Identificación de los patógenos y artrópodos que afectan la sanidad de las orquídeas silvestres y cultivadas.

German Rivera Coto. Catedrático de la Universidad Nacional. Ha trabajado por 30 años como Fitopatólogo en programas de investigación, docencia y extensión universitaria. En los últimos 20 años ha orientado su trabajo hacia la capacitación en el cultivo de las orquídeas y la investigación de los problemas fitopatológicos de la familia Orchideaceae, particularmente sobre enfermedades fungosas. Es autor de un libro sobre cultivo de las orquídeas con énfasis en los problemas sanitarios, varios artículos de revistas y ponencias en congresos nacionales e internacionales.

Gilberto Corrales Moreira. Profesor jubilado de la Universidad Nacional y de la Universidad de Costa Rica, donde fue docente, investigador y extensionista en entomología agrícola. En los últimos años ha colaborado ad honorem en el proyecto de investigación: Identificación de los patógenos y artrópodos que afectan la sanidad de las orquídeas en poblaciones silvestres y cultivadas. Producto de su trabajo ha realizado varias publicaciones sobre plagas de orquídeas. 